\title{
Effects of Different Parameters on Initiation and Propagation of Stress Corrosion Cracks in Pipeline Steels: A Review
}

\section{M.A. Mohtadi-Bonab}

Department of Mechanical Engineering, University of Bonab, Velayat Highway, Bonab 5551761167, Iran; m.mohtadi@bonabu.ac.ir; Tel.: +98-9144203460

Received: 27 March 2019; Accepted: 20 May 2019; Published: 22 May 2019

\begin{abstract}
The demand for pipeline steels has increased in the last several decades since they were able to provide an immune and economical way to carry oil and natural gas over long distances. There are two important damage modes in pipeline steels including stress corrosion cracking (SCC) and hydrogen induced cracking (HIC). The SCC cracks are those cracks which are induced due to the combined effects of a corrosive environment and sustained tensile stress. The present review article is an attempt to highlight important factors affecting the SCC in pipeline steels. Based on a literature survey, it is concluded that many factors, such as microstructure of steel, residual stresses, chemical composition of steel, applied load, alternating current (AC) current and texture, and grain boundary character affect the SCC crack initiation and propagation in pipeline steels. It is also found that crystallographic texture plays a key role in crack propagation. Grain boundaries associated with $\{111\} \mid$ rolling plane, $\{110\} \|$ rolling plane, coincidence site lattice boundaries and low angle grain boundaries are recognized as crack resistant paths while grains with high angle grain boundaries provide easy path for the SCC intergranular crack propagation. Finally, the SCC resistance in pipeline steels is improved by modifying the microstructure of steel or controlling the texture and grain boundary character.
\end{abstract}

Keywords: stress corrosion cracking; residual stress; AC current density; crystallographic texture; intergranular and transgranular cracks

\section{Introduction}

The demand for energy has increased in recent decades which forced the industry to develop high resistance pipeline steels [1-3]. Such steels show better mechanical properties and a higher corrosion resistance compared with normal carbon steels. However, these steels still suffer from two important failure modes including hydrogen induced cracking (HIC) and stress corrosion cracking (SCC) [4-6]. There are numerous studies in the literature focused on these failure modes. The SCC has been recognized as one of the main important failure modes in humid environments and causes a huge amount of economical loss and environmental disasters all around the world. The SCC susceptibility in pipeline steels depends on various factors such as the microstructure of steel, distribution of inclusions and precipitates inside the steel, texture and micro-texture of steel, chemical composition of steel, $\mathrm{pH}$ of the oil and gas which is transported, the $\mathrm{pH}$ of soil and environment where the pipeline steel is buried, and many other factors. Importance of the SCC in pipeline failure motivated us to write this review paper. This paper concentrates on different factors affecting the SCC crack nucleation and propagation in pipeline steel and looks for new ways to increase the resistance of pipeline steels to the SCC. Tables 1 and 2 show the chemical composition and mechanical properties of common used pipeline steels (API X60, API X65, API X70, API X80 and L360NS). 
Table 1. Chemical composition of API X60, X65, X70, X80 and L360NS pipeline steel (wt. \%) [7-9].

\begin{tabular}{ccccccccccc}
\hline Pipeline Steel & $\mathbf{C}$ & $\mathbf{M n}$ & $\mathbf{S i}$ & $\mathbf{N b}$ & $\mathbf{M o}$ & $\mathbf{T i}$ & $\mathbf{C r}$ & $\mathbf{C u}$ & $\mathbf{N i}$ & $\mathbf{V}$ \\
\hline X60 & 0.052 & 1.50 & 0.15 & 0.067 & 0.096 & 0.022 & 0.07 & 0.18 & 0.19 & 0.001 \\
X65 & 0.081 & 1.54 & 0.33 & 0.04 & - & 0.002 & - & 0.18 & - & 0.001 \\
X70 & 0.025 & 1.65 & 0.26 & 0.068 & 0.175 & 0.015 & 0.07 & 0.21 & 0.08 & 0.001 \\
X80 & 0.056 & 1.90 & 0.31 & 0.046 & 0.213 & 0.018 & - & 0.044 & 0.221 & - \\
L360NS & 0.12 & 1.50 & 0.25 & - & 0.02 & - & 0.07 & 0.08 & 0.04 & - \\
\hline
\end{tabular}

Table 2. Mechanical properties of API X60, X65, X70, X80 and L360NS pipeline steels [8-10].

\begin{tabular}{cccc}
\hline Pipeline Steel & Yield Strength (MPa) & Tensile Strength (MPa) & Elongation (\%) \\
\hline X60 & 520 & 610 & 33 \\
X65 & 568 & 650 & 32 \\
X70 & 615 & 720 & 29 \\
X80 & 640 & 780 & 25 \\
L360NS & 380 & 510 & 41 \\
\hline
\end{tabular}

The microstructure of API X60 and X70 pipeline steels has been mainly composed of polygonal and acicular ferrite. Moreover, there are some particles of martensite in the microstructure of both steels [7]. The microstructure of X65 steel includes mostly ferrite and some pearlite [10]. When the strength of pipeline steel increases, the microstructure becomes different from other types of steels. For example, the microstructure of X80 and X100 pipeline steels is mainly formed from ferrite and bainite $[11,12]$. There are also some martensite particles in the microstructure of both X80 and X100 steels. The microstructure of L360NS pipeline steel has been composed of white blocky polygonal ferrite, gray irregular blocky quasi-polygonal ferrite and black blocky pearlite colony [10].

\section{Explanation of SCC and HIC}

The HIC and the SCC are categorized as two types of corrosion that occur in pipeline steels. Since they have a close correlation, it is necessary to define both. In order to have an accurate definition of the HIC and the SCC, it would be better to explain the corrosion concept. Corrosion is the material degradation due to environmental effects. During the corrosion process, electrons are released due to the metal dissolution at anodic site [13]. Such electrons transfer to the cathode, where oxygenated water is reduced to hydrogel ions. The following overall reactions occur during the metal corrosion.

$$
\text { Anodic dissolution: } \mathrm{Fe} \rightarrow \mathrm{Fe}^{+2}+2 \mathrm{e}^{-}
$$

Figure 1 shows how a rust begins with the oxidation of iron to ferrous ions. The rust formation is a very complicated process, which begins with the oxidation of iron.

$$
\begin{gathered}
\text { Oxidation at anode: } 2 \mathrm{H}_{2} \mathrm{O}(\mathrm{l}) \rightarrow \mathrm{O}_{2}(\mathrm{~g})+4 \mathrm{H}^{+}(\mathrm{aq})+4 \mathrm{e}^{-} \\
\text {Oxygen reduction in neutral or alkalis media: } \mathrm{O}_{2}+2 \mathrm{H}_{2} \mathrm{O}+4 \mathrm{e}^{-} \rightarrow 4 \mathrm{OH}^{-} \\
\text {Oxygen reduction in acidic media: } \mathrm{O}_{2}+4 \mathrm{H}+4 \mathrm{e}^{-} \rightarrow 2 \mathrm{H}_{2} \mathrm{O} \\
\text { Overall corrosion reaction: } \mathrm{Fe}+2 \mathrm{H}^{+} \rightarrow \mathrm{Fe}^{+2}+\mathrm{H}^{2}
\end{gathered}
$$

The SCC cracks are cracks that are induced due to the combined effect of the corrosive environment and sustained tensile stress. The tensile stress can be directly applied inside the pipeline or can be in the form of residual tensile stress. Therefore, three parameters including, a susceptible material (pipeline steel), a specific chemical species (environment), and tensile stress are required for crack nucleation and propagation. Therefore, the SCC is a type of environmentally assisted cracking (EAC), which is of great interest to the oil and gas pipeline manufactures. Recently, thousands of colonies of 
the SCC cracks have been observed in pipeline steels. Such cracks usually become dormant at depth of $1 \mathrm{~mm}$. However, sometimes these cracks result in failure of pipeline by crack propagation [14]. Figure 2 shows effective factors influencing SCC crack initiation in pipeline steels.

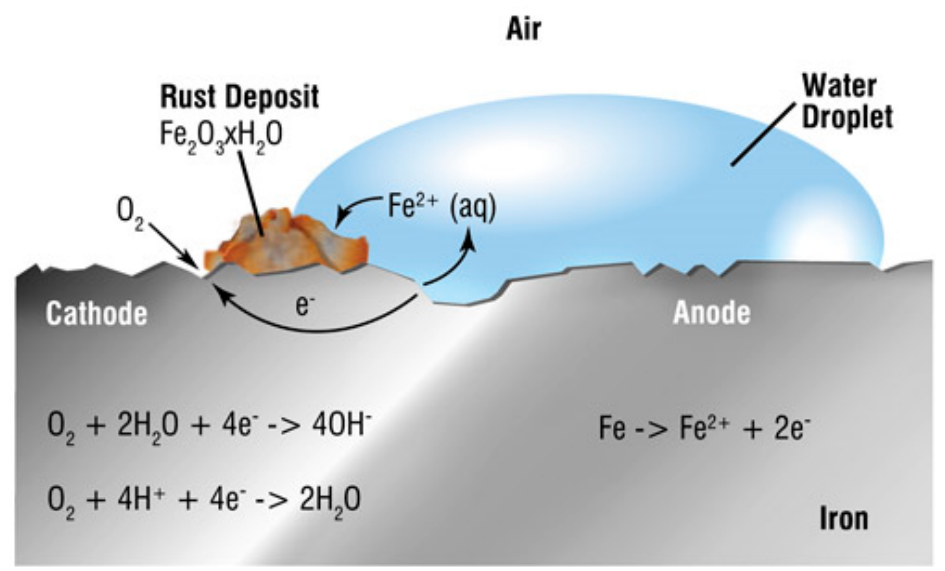

Figure 1. Formation of rust by the oxidation of iron to ferrous ions [13]. Reproduced with permission from [13], Noria Corporation and Machinery Lubrication, 2018.

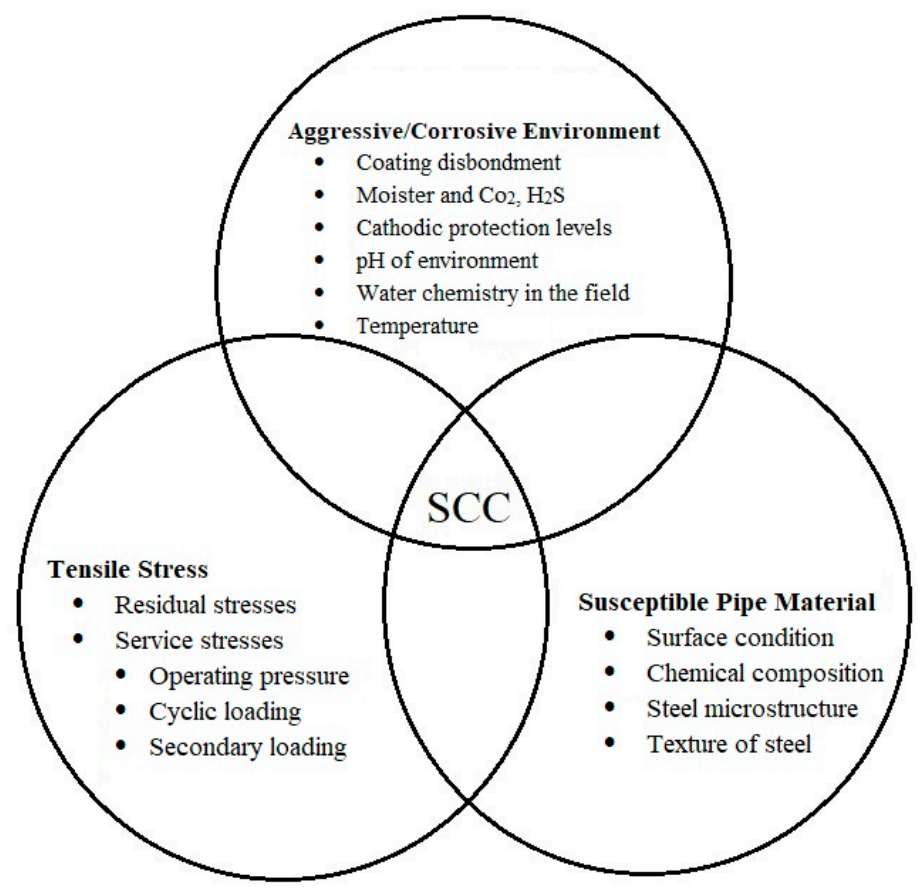

Figure 2. Effective factors for the stress corrosion cracking (SCC) crack initiation in pipeline steels.

Several factors such as microstructure, chemical composition, residual stress, texture of steel, water chemistry in the field, applied stress, $\mathrm{pH}$ of environment and AC current density may affect the SCC crack nucleation and propagation in pipeline steels, see Figure 2 [15-20]. Two types of corrosion happen in pipeline steels [21]. The first one is the sweet corrosion, which happens due to the presence of $\mathrm{CO}_{2}$. The sweet corrosion [21] in carbon steels is formed in an acidic solution by mixing the $\mathrm{CO}_{2}$ and water. The corrodant material is $\mathrm{H}^{+}$which is derived from $\mathrm{H}_{2} \mathrm{CO}_{3}$. The $\mathrm{CO}_{2}$ gas is entered during some processes such as injection of $\mathrm{CO}_{2}$ gas into the steel during the recovery operation. The sweet corrosion starts with the reaction of Fe and $\mathrm{CO}_{2}$. This reaction can be written as follows:

$$
\mathrm{Fe}+\mathrm{CO}_{2} \rightarrow \mathrm{FeCO}_{2}
$$


The reaction between the adsorbed surface complex with water produces $\mathrm{Fe}^{2+}$ (aq) and $\mathrm{H}_{2} \mathrm{CO}^{3}$. This reaction provides the cathodic reactant $\mathrm{H}^{+}$during dissociation. The cathodic reaction can be written as follows:

$$
\begin{gathered}
2 \mathrm{H}^{+}(\mathrm{aq})+2 \mathrm{e}^{-} \rightarrow \mathrm{H}_{2} \\
2 \mathrm{H}_{2} \mathrm{CO}_{3}+2 \mathrm{e}^{-} \rightarrow \mathrm{H}_{2}+2 \mathrm{HCO}_{3}^{-}
\end{gathered}
$$

The dissociation of $\mathrm{H}_{2} \mathrm{CO}_{3}$ in solution creates hydrogen ion for cathodic reaction.

$$
\mathrm{H}_{2} \mathrm{CO}_{3}+\mathrm{e}^{-} \rightarrow \mathrm{H}^{+}+\mathrm{HCO}_{3}^{-}
$$

Several studies have been focused on sweet corrosion [21], however, the mechanism of a cathodic reaction has not been fully understood. It was shown that when a $\mathrm{pH}$ value is lower than 4 , the hydrogen reduction is the dominant mode for the corrosion. However, when the $\mathrm{pH}$ value varies between 4 and 7 , the adsorbed $\mathrm{H}_{2} \mathrm{CO}_{3}$ reduction is considerable. This type of corrosion is called sweet corrosion since it occurs with the absence of hydrogen sulphide or high levels of hydrogen sulphide. Carbon dioxide or carbonic acid are the main causes of sweet corrosion.

The second type and more common type of corrosion occurs owing to the presence of hydrogen sulphide $\left(\mathrm{H}_{2} \mathrm{~S}\right)$. Hydrogen sulphide which is present in oil and natural gas is decomposed to $\mathrm{H}^{+}$and $\mathrm{HS}^{-}$. HS ion acts as a hydrogen recombination poison and avoid hydrogen molecule formation [7]. The following reactions occur:

$$
\begin{aligned}
& \mathrm{H}_{2} \mathrm{~S} \rightarrow \mathrm{HS}^{-}+\mathrm{H}^{+} \\
& \mathrm{HS}^{-} \rightarrow \mathrm{S}^{-2}+\mathrm{H}^{+}
\end{aligned}
$$

Hydrogen atoms in the forms of protons get electrons from the iron and converted to the hydrogen atoms based on the following equations:

$$
\begin{gathered}
\mathrm{H}^{+}+\mathrm{e}^{-} \rightarrow \mathrm{H}_{\mathrm{ads}} \\
\mathrm{H}_{\mathrm{ads}}+\mathrm{H}_{\mathrm{ads}} \rightarrow \mathrm{H}_{2}
\end{gathered}
$$

It is worth mentioning that the hydrogen atoms are accumulated at microstructural defects such as empty spaces between inclusions and precipitates and metal matrix. The hydrogen atoms are combined at these regions and create a high amount of pressure. When this pressure reaches a critical value, the cracks initiate. Such cracks are known as hydrogen-induced cracks. The cavities or empty spaces are formed between inclusions and the metal matrix due to the difference between their thermal expansion coefficients. These cavities are formed during solidification of slabs or hot rolling process and can capture hydrogen atoms due to their small sizes. When the hydrogen atoms are accumulated in these areas, they combine to make hydrogen molecules, which make a high amount of pressure. The following equation shows the Gibbs free energy for hydrogen atoms combination.

$$
\Delta_{r} G_{H}=\Delta_{r} G_{H}^{\Theta}+R T \ln \frac{p_{H_{2}} / p^{\Theta}}{C_{H}^{2}}
$$

In the above equation, $\Delta_{r} G_{H}^{\Theta}$ is the reaction standard Gibbs free energy, $T$ and $\mathrm{R}$ are the reaction temperature and gas constant and $C_{H}$ and $p^{\Theta}$ re the concentration of hydrogen atoms near the inclusion and standard atmospheric pressure. When the concentration of $\mathrm{H}$ atoms around the inclusions reach a certain value, the reaction will occur and hydrogen molecules are formed. Based on the above equation, the increase of $C_{H}$ at the reaction interface will decrease the reaction Gibbs free energy and further leads to the production of $\mathrm{H}_{2}$ molecules. Hydrogen molecule formation creates a high amount of pressure and this results in hydrogen-induced cracks. 


\section{Role of Microstructure on the SCC Cracks}

Microstructure of pipeline steel plays an important role in the SCC crack propagation. In general, hard and brittle phases ease the SCC crack propagation. There are a few papers in the literature focused on the role of microstructure on the SCC crack propagation. Most of the papers have discussed the role of microstructure on the nature of crack. For instance, Zhu et al. [22] investigated the mechanism of failure by the SCC in X80 pipeline steel in high pH carbonate and bicarbonate solution. These authors concluded that the nature of the SCC cracks mainly depends on the microstructure of steel. They observed that when the local microstructure of steel has been formed from bulky polygonal ferrite and granular bainite in a high $\mathrm{pH}$ solution, the nature of the crack is intergranular. However, when the local microstructure changes to the fine acicular ferrite and granular bainite, both intergranular and trangranular types of the SCC cracks are observed. Moreover, they implied that the microstructure of steel has a decisive role in transgranular SCC cracking and the probability of transgranular crack propagation increases with a decrease of $\mathrm{pH}$ solution. As seen in Figure 3a,b, both types of cracks are seen in the cross section of X80 pipeline steel after slow strain rate tensile (SSRT) test in high $\mathrm{pH}$ solution. At the crack initiation stage, the crack type is intergranular; however, both types of cracks are observed at the later stage.
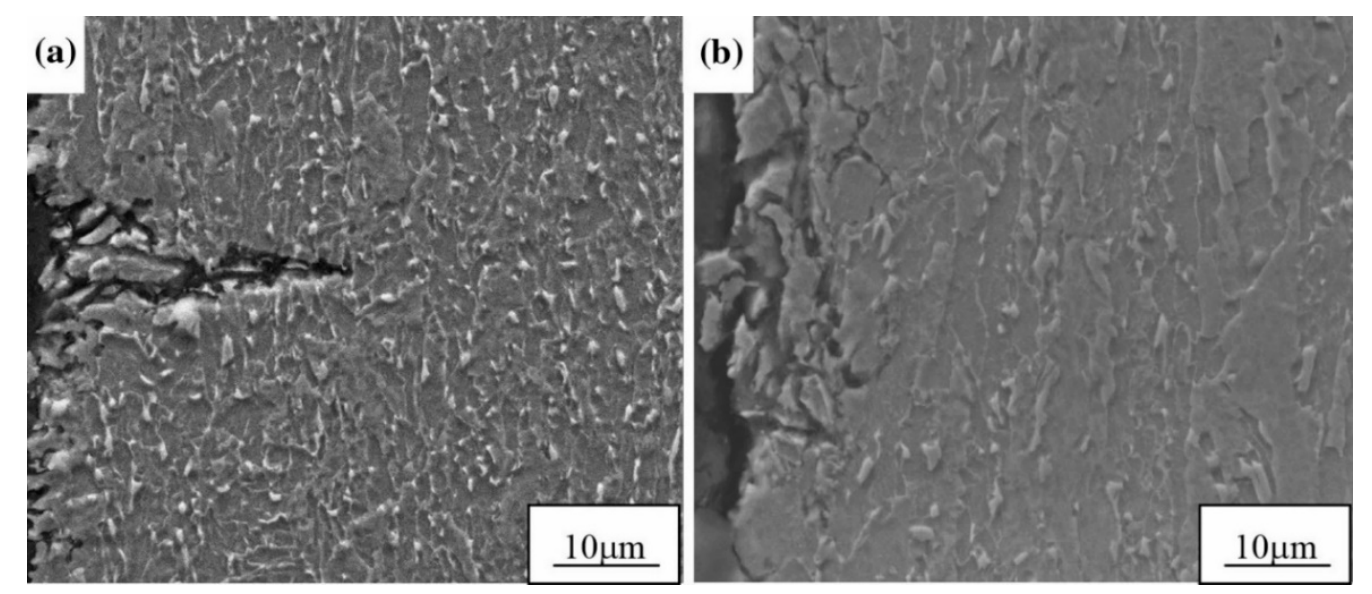

Figure 3. (a,b) SCC cracks in the cross section of X80 pipeline steel after SSRT test in high $\mathrm{pH}$ solution [22]. Reproduced with permission from [22], Springer Nature, 2014.

In another study, Gonzalez et al. [23] studied the effects of microstructure on the SCC behavior in HSLA steel. Their results documented that the microstructure of steel play a key role in the SCC behavior. Based on their findings, the type of microstructure is very important in transgranular crack propagation, while other metallurgical parameters including grain size and grain boundary character become determinative factors during intergranular cracking. It has been reported that the SSC susceptibility directly depends on the hardness, microstructure and chemical composition of steel [24]. Typically, the SSC cracks are internally propagated in intergranular manner and show little crack branching; however, some cracks have been also reported in transgranular mode [25]. Roffey et al. [26] investigated the SCC in an austenitic stainless steel hydrocarbon gas pipeline and concluded that transgranular SCC cracks initiate from corrosion pits from the internal and external surfaces and are divided to some branches, see Figure $4 \mathrm{a}, \mathrm{b}$.

Elboujdaini et al. [27] carried out research on the role of metallurgical factors on the SCC susceptibility. They found that the SCC cracks usually initiate from corrosion pits and pits nucleate from sulfides. Therefore, sulfide precipitates, inclusions and stringers can affect the SCC susceptibility in pipeline steel. Figure 5a-c shows a SCC crack initiating from a corrosion pit in X65 pipeline steel. 

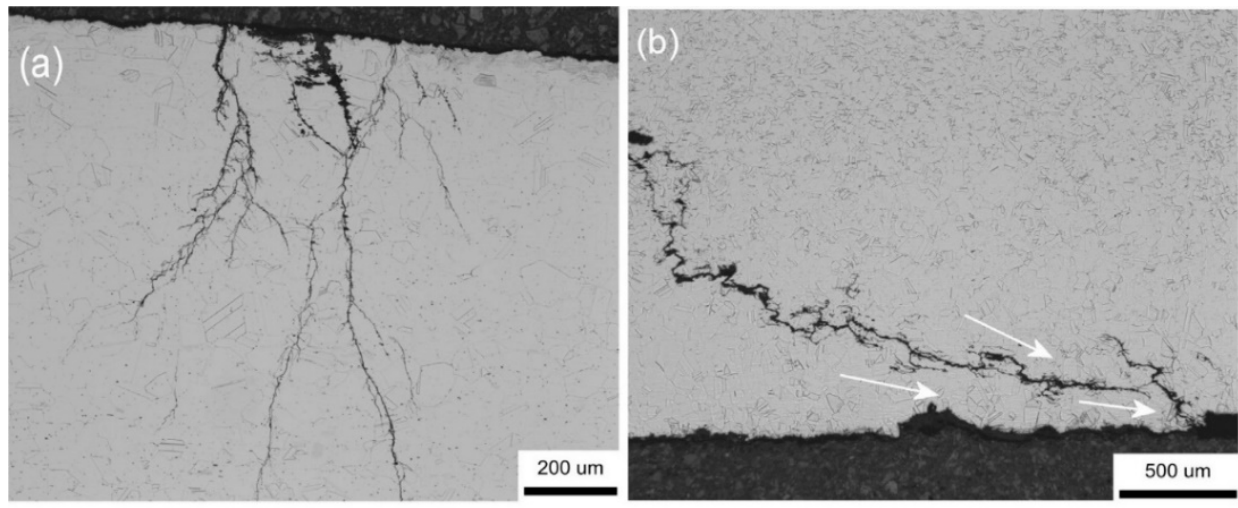

Figure 4. Transgranular type of cracks from corrosion pits on (a) internal surface, and (b) external surface [26]. Reproduced with permission from [26], Elsevier, 2014.

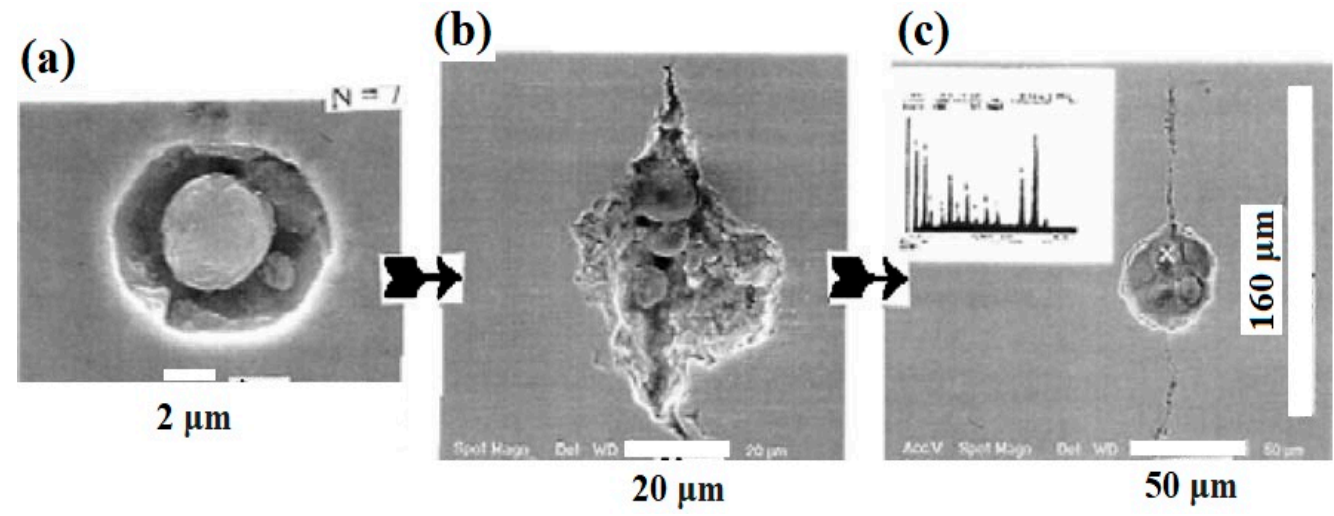

Figure 5. (a) Pit formation from an inclusion in X65 pipeline steel, (b) SCC crack initiation from a pit and (c) EDS analysis on the inclusion showing the existence of $\mathrm{Na}, \mathrm{Mg}, \mathrm{Al}, \mathrm{Si}, \mathrm{P}, \mathrm{S}, \mathrm{Cl}$, K, and Ca elements [27]. Reproduced with permission from [27], Springer Nature, 2009.

\section{Role of Stress Intensity Factor (SIF) in SCC and HIC Crack Propagation}

SCC crack initiation and propagation in pipeline steel occur in three stages, see Figure 6 [28]. In the first step, small SCC cracks continuously initiate and coalesce. Initiation of these small cracks occurs in a large proportion of lifetime of pipeline steel. In the second step, the initiated small cracks propagate rapidly. This step is characterized by a function of stress intensity factor (SIF). SIF which is used in materials with small scale yielding at a crack tip represents the state of stress near the crack tip. In linear elastic fracture mechanics, it is used to explain the intensification of applied stress at the crack tip and is an important factor in characterizing the driving force and the crack propagation rate [29]. It basically depends on the geometry of the crack, location of the crack and applied load. In the third step, the material fails by rapid crack growth. Crack branching is one of the main characteristics of SCC cracks in pipeline steels. Two types of branching including micro-branching and macro-branching are observed in pipeline steels. In macro-branching, the main crack is divided to two running cracks and crack growth rate is independent from the crack length. The critical SIF for crack branching should exceed $\sqrt{2}$ two times of SIF for the crack propagation. In micro-branching, a main SCC crack splits into several small cracks at intervals of the order of one grain diameter. This phenomenon occurs when the critical SIF reaches at least $\sqrt{2}$ times of the subcritical value of the stress intensity [30]. The lifetime of pipeline steel is clearly determined by the second step. In fatigue corrosion, according to figure below, one process of fast crack propagation in step two is started when the maximum SIF at the crack tip exceeds the threshold SIF for SCC (KISCC). Another process of fast crack propagation occurs when the maximum stress intensity range $(\Delta K)$ exceeds the fatigue threshold $\left(\Delta K_{\mathrm{th}}\right)$. 


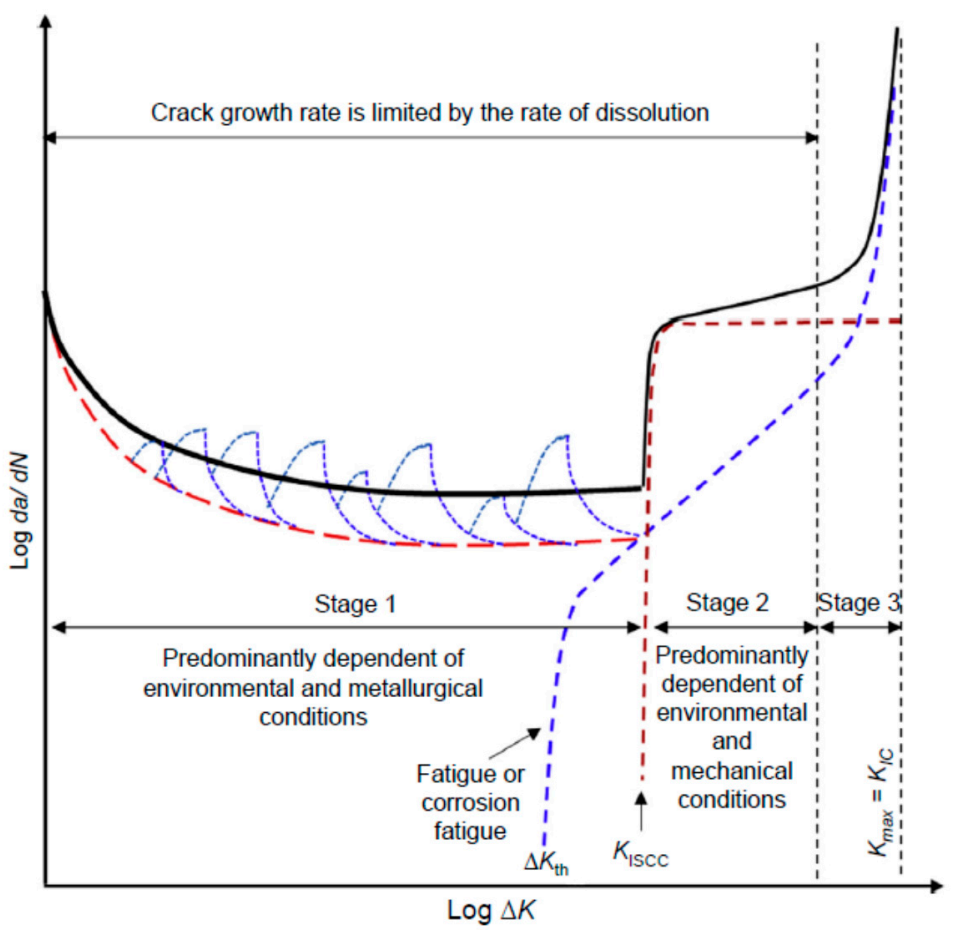

Figure 6. Effect of $\Delta K$ upon SCC velocity of pipeline steel exposed to carbonate, bicarbonate solution [28]. Reproduced with permission from [28], Elsevier, 2017.

Besides the SCC phenomenon, the SIF plays a key role in HIC crack propagation in pipeline steels. Costin et al. [31] reported that the threshold SIF $\left(\mathrm{K}_{\text {th }}\right)$ range for crack propagation is between $1.56 \mathrm{MPa} \sqrt{m}$ and $4.36 \mathrm{MPa} \sqrt{m}$. This range is lower than the $\mathrm{K}_{\mathrm{th}}$ value which is calculated for ferrous alloys. This shows that subcritical HIC cracks propagate at micro-scale at lower SIFs.

\section{Role of Surface Films in SCC}

One of the important factors affecting SCC in pipeline steels is surface films. During the corrosion reaction, metallic iron is oxidized to the $\mathrm{Fe}^{2+}$ due to the electrochemical potential. There are some cracks at this oxide layer and at the interface between the oxide and the steel [32]. Figure 7 shows that SCC cracks initiated from the oxide film. The nature of these cracks is from transgarular. When the oxide films are cracked, the SCC cracks penetrated into the steel in transgraular manner. Therefore, two types of SIFs can be considered for SCC cracks in pipeline steels [28]. The first one is related to the external load while the oxide film induces the SIF in the second type. When the critical condition for film-induced SIF, the crack initiation and propagation will occur. The film-induced SIF can be considered as a driving force for SCC crack propagation. 

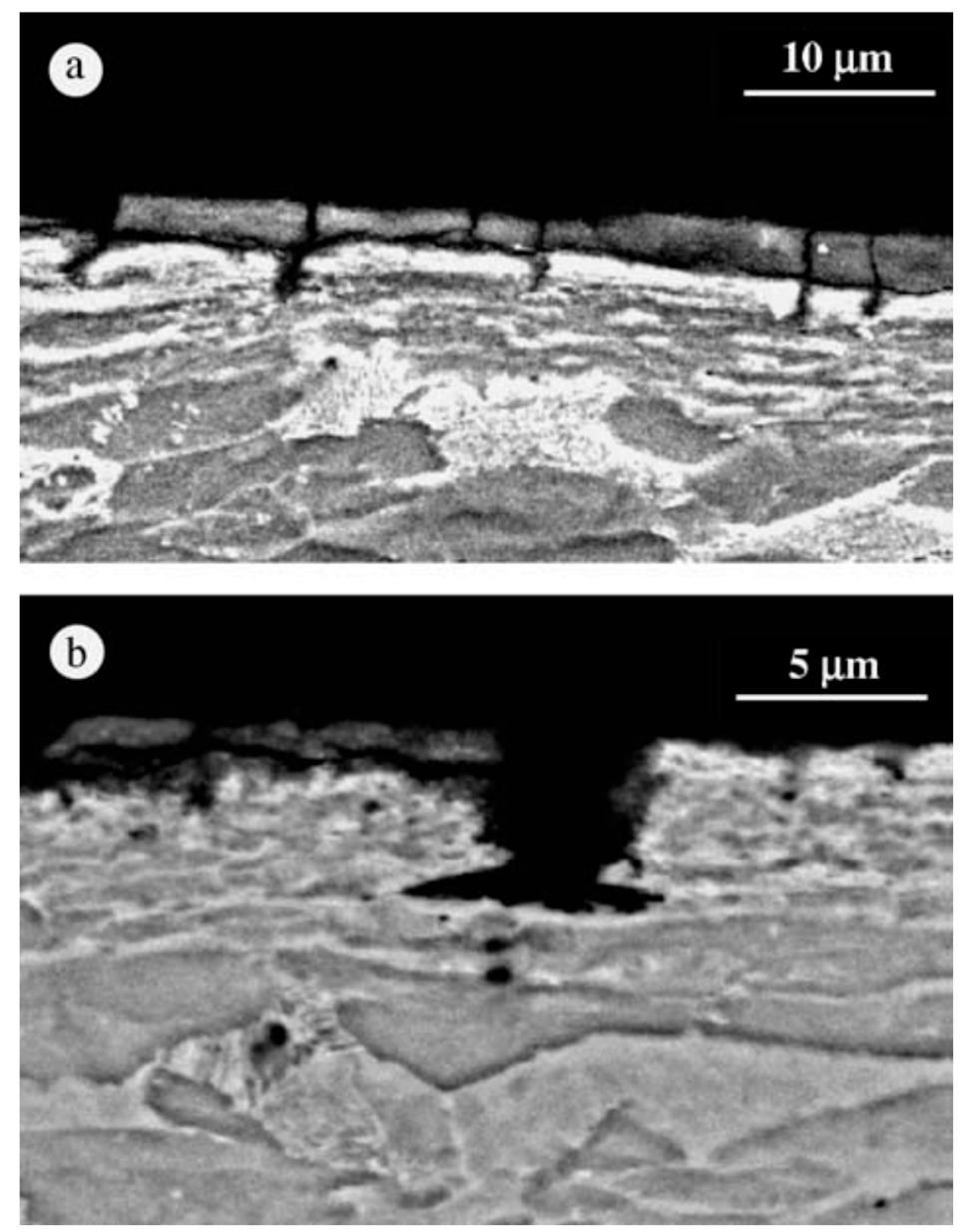

Figure 7. Initiation of transgranular SCC cracks from the surface oxide: (a) region 1, and (b) region 2 [32]. Reproduced with permission from [32], Elsevier, 2003.

\section{Effect of Residual Stress on the SCC Crack Propagation}

Beside the role of microstructure of pipeline steel on the SCC crack propagation in pipeline steel, the effect of tensile and compressive residual stresses on the SCC crack propagation is undeniable. Residual stresses are mainly developed during the manufacturing of forming and welding process in pipeline steels. Such stresses are high and sometimes reach yield stress of steel. Tensile residual stresses provide a driving for the SCC crack propagation while the compressive residual stresses have an opposite effect. In this field of study, Chen et al. [33] investigated the role of residual stresses on the SCC susceptibility in pipeline steel in neutral $\mathrm{pH}$ solution. These authors found that tensile residual stress gives a high amount of mechanical driving force for crack initiation and short crack propagation. These authors also showed that the SCC cracks are blunted by plastic deformation when the crack is propagated in a $45^{\circ}$ where the shear stress for the plastic deformation is highest, see Figure $8 \mathrm{a}, \mathrm{b}$. 


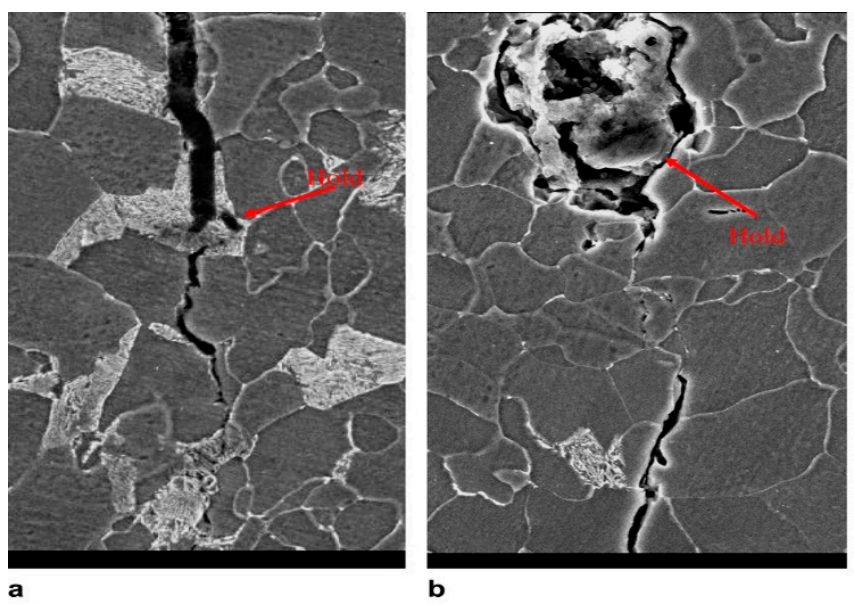

Figure 8. (a,b) Crack tip morphology after the pipeline specimens subjected to constant load for 7 days in different soil solutions [33]. Reproduced with permission from [33], Elsevier, 2007.

\section{Role of AC Current on the SCC Susceptibility}

Nowadays, pipeline steels are usually buried parallel with the electric power lines or electrified railways due to the limitation space [34]. Therefore, there is a possibility for the flowing of the AC current to the soil encompassed pipeline. Such AC flow results in AC corrosion of a pipeline where the coating is disbonded [35]. There are some investigations showing that AC interference increases the corrosion rate in metal alloys [36-38]. It has also been reported that AC current may break down the insulation layer of pipeline steel and destroy the cathodic protection system [39-41]. Zhu et al. [34] studied the role of AC current on the SCC susceptibility in carbonate/bicarbonate solution in X80 pipeline steel using SSRT experiment. They concluded that AC current plays a significant role on the SCC behavior. They observed that when there is no AC current, the SCC cracks propagate in intergranular manner and its mechanism is from the anodic dissolution. However, with the presence of AC current, the SCC susceptibility is increased and the SCC cracks propagate in transgranular manner at high AC current densities. In another study, Wan et al. [42] investigated the effect of alternating current on the SCC mechanism in X80 pipeline steel in near-neutral solution. The results of their research showed that crack propagation in X80 steel does not depend on the AC current and its mechanism shows a transgranular fracture feature. However, they observed that the depth of crack propagation is enhanced with the increase of AC current. Figure 7 depicts the fracture surfaces of X80 steel after SSRT experiment. As shown in the Figure 9a, there is no crack in the specimen tested in the air. However, there are small cracks in specimens tested in NS4 solution without AC current indicating SCC susceptibility, as shown in the Figure $9 \mathrm{~b} . \mathrm{NS}_{4}$ solution or near-neutral soil solution $(\mathrm{pH}=7)$ is used as a test solution for SCC experiment. It is prepared by mixing distilled water and pure chemical reagent. The chemical composition of $\mathrm{NS}_{4}$ solution is shown in Table 3.

It is important to note that the number and the length of the secondary cracks increase with the increase of AC current density see the Figure $9 \mathrm{c}, \mathrm{d}$. When the AC current density reaches 30 and $50 \mathrm{~A} / \mathrm{m}^{2}$, as shown in the Figure $9 \mathrm{e}, \mathrm{f}$, the secondary cracks become wide signifying an increased SCC susceptibility. As seen in these figures, some cracks nucleated from pitting illustrating that anodic dissolution affected the SCC in X80 steel [42].

Table 3. $\mathrm{NS}_{4}$ solution composition (g/L) [43].

\begin{tabular}{ccccc}
\hline $\mathrm{NS}_{4}$ solution & $\mathrm{KCl}$ & $\mathrm{NaHCO}_{3}$ & $\mathrm{CaCl}_{\mathbf{2}} \cdot \mathbf{2} \mathrm{H}_{\mathbf{2}} \mathrm{O}$ & $\mathbf{M g S O}_{4} \cdot \mathbf{7} \mathrm{H}_{\mathbf{2}} \mathrm{O}$ \\
\hline- & 0.122 & 0.483 & 0.181 & 0.131 \\
\hline
\end{tabular}



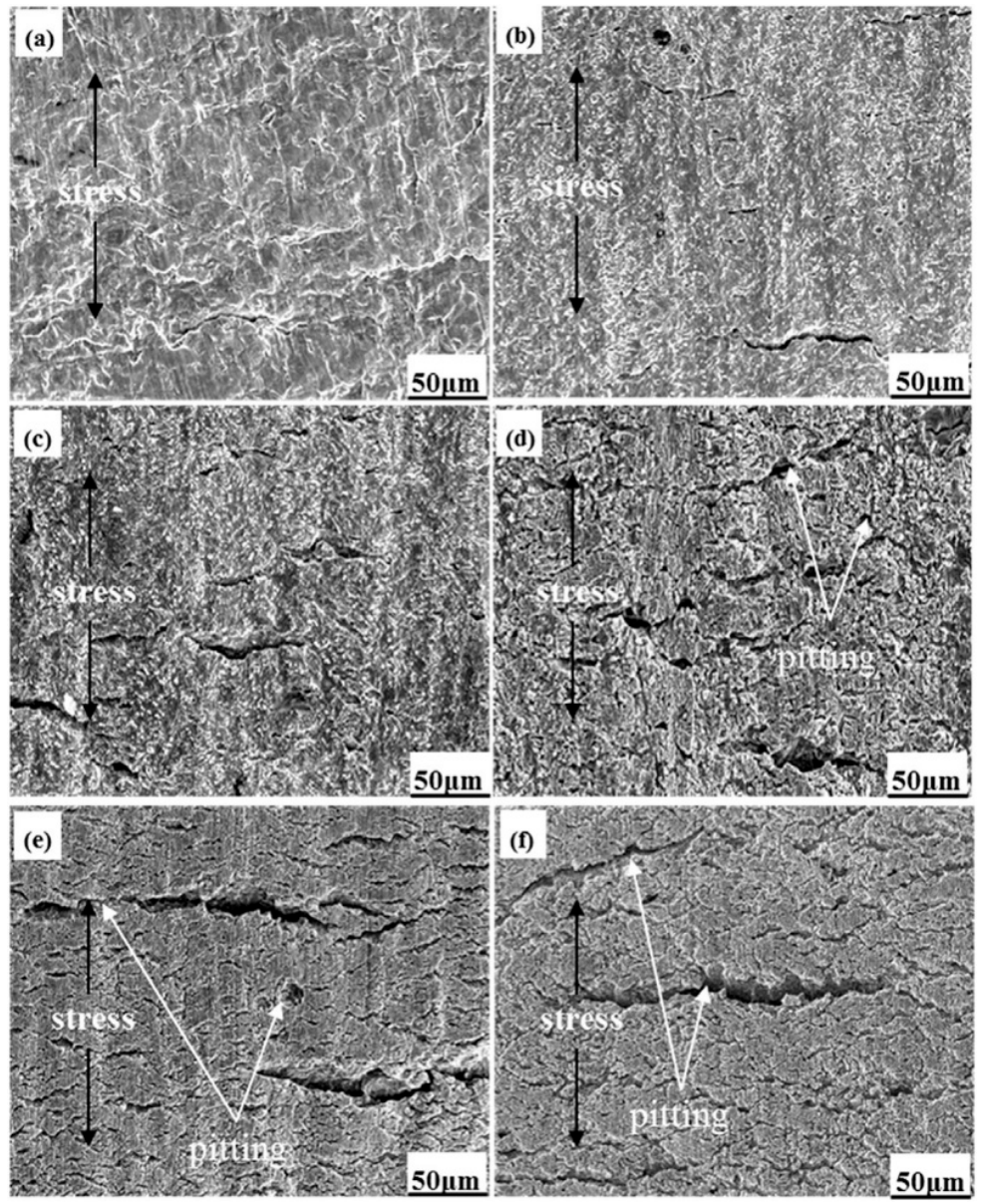

Figure 9. SEM image of fracture surfaces of X80 pipeline steel in air and NS4 solution in (a) in air, (b) $0 \mathrm{~A} / \mathrm{m}^{2}$, (c) $5 \mathrm{~A} / \mathrm{m}^{2}$, (d) $10 \mathrm{~A} / \mathrm{m}^{2}$, (e) $30 \mathrm{~A} / \mathrm{m}^{2}$ and (f) $50 \mathrm{~A} / \mathrm{m}^{2}$ [42]. Reproduced with permission from [42], Elsevier, 2017.

It is worth mentioning that the mechanism of AC current on SCC has not been fully understood. However, AC current transfers between pipeline steels and soil when there is a coating defect on pipeline surface and this leads to the AC corrosion [44]. The corrosion potential is negatively shifted by $\mathrm{AC}$ current and this phenomenon degrades the steel passivity in carbonate/bicarbonate solution. When the AC current increases, the corrosion type will change from uniform to pitting. Zhu et al. [45] studied the effect of short term AC current on SCC susceptibility in pipeline steel and observed several intergranular SCC cracks and the anodic dissolution of steel was the main mechanism for SCC. They concluded that when the AC current increases, the rate of intergranular crack nucleation from corrosion pits will increase as well.

\section{Type of Environment on the SCC Behavior}

Pipeline steels are usually used in various environments. For example, API 5L X60, X65 and X70 pipeline steels carry oil and natural gas in sour environments having a high amount of $\mathrm{H}_{2} \mathrm{~S}$ and $\mathrm{CO}_{2}$ with low $\mathrm{pH}$ value. An acidic environment, containing $\mathrm{H}_{2} \mathrm{~S}, \mathrm{CO}_{2}$, and water, promotes corrosion and the $\mathrm{H}_{2} \mathrm{~S}$ enhances the absorption of hydrogen into the pipeline steel by the corrosion reaction as well. Some types of pipeline steels pass from sea water which has salt. Chloride ions are considered as one of the common atmospheric corrosive agent [46,47]. One of the environments is the deep sea water which applies a hydrostatic pressure to the pipeline steel. Even though there are few papers focused in this field, the deep sea water has a crucial effect on SCC susceptibility in pipeline steel. It has been reported that the SCC in land soil are dived into two types. The first type happens due to the effect 
of anodic dissolution in high $\mathrm{pH}$ solution among the grain boundaries $[11,48,49]$. The second one, however, occurs due to the combination effect of anodic dissolution and hydrogen embrittlement in near neutral $\mathrm{pH}$ solution [50,51]. In subsea environments, when the coating on the pipeline surface is destroyed, the permeation of seawater in the gaps will promote the peeling of the coating resulting in a complicated and more severe corrosion in pipeline steel [52].

Sun et al. [53] carried out an interesting study on SCC susceptibility in deep and shallow sea water on X70 pipeline steel. They showed that the SCC susceptibility first decreased, reached minimum amount at $15 \mathrm{MPa}$ and then increased with the increase of hydrostatic pressure. In other word, the SCC susceptibility is the lowest at $1500 \mathrm{~m}$ deep sea environment; however, it reaches the its highest amount at $3000 \mathrm{~m}$.

Moreover, the electrolyte has a considerable effect on SCC susceptibility in pipeline steels. It has been reported that the electrolyte $\mathrm{pH}$ has a key role in determining the nature of SCC crack in pipeline steels [54]. The type of SCC crack is intergranular when concentrated carbonate electrolytes with high $\mathrm{pH}$ is present as a composition of environment. It is worth-mentioning that transgranular type of SCC crack occurs in pipeline steels with dilute electrolytes [55]. One should consider that the main components of ground electrolytes contain carbonate/bicarbonate, sulfate, chloride and nitrate onions. Moreover, some soils are acidic with different types of compositions and concentrations. The effect of each on SCC should be considered separately.

One of the factors affecting the SCC susceptibility is the produced hydrogen inside the pipeline steel. The correlation between the hydrogen effect and anodic dissolution has not been completely recognized. However, it appears that hydrogen may have a destructive effect on SCC susceptibility due to the hydrogen embrittlement phenomenon. Lu et al. [56,57] studied the effect of hydrogen on SCC susceptibility and reported that hydrogen restricts pipeline steel dissolution in near-neutral pH water. However, unexpected results were proposed by Liu et al. [58]. These authors investigated the SCC susceptibility in X70 steel under cathodic protection in an acidic and near-neutral solution by using SSRT experiment. The results of their findings proved that hydrogen induced plasticity has a positive impact on SCC susceptibility by releasing the stress concentration at the crack nucleation sites and reducing the stress intensity. However, they reported that in order to postpone the crack initiation and propagation, the applied potential should be within the high SCC susceptibility potential range.

The sulphur element has a key role on SCC susceptibility in pipeline steels. One can consider its effect in two different ways. First, it plays an important role inside the microstructure of steel. It has been reported that the sulfur element has a detrimental effect on HIC susceptibility by creating MnS inclusion $[8,59,60]$. This type of inclusion usually has an elongated shape and provides regions with high stress concentration. Therefore, this inclusion is considered as the HIC crack initiation site. From the second viewpoint, sulphur element provides a corrosive environment for pipeline steel. Fan et al. [9] investigated the SCC susceptibility in L360NS pipeline steel in sulfur environment and concluded that the existence of sulfur element considerably increases the SCC susceptibility. As shown in Figure 10, these authors modeled the SCC behavior in L360NS pipeline steel in sulfur melting cladding condition and observed that $\mathrm{H}^{+}$ion permeates into the substrate in region with high stress concentration. This permeation breaks the corrosion product film and the surface of pipe steel is corroded continuously. The combined effects of corrosion and hydrogen diffusion degrade the mechanical properties of steel and the pipeline steel fractures under the stress.

Moreover, an applied load plays an important role during crack initiation and propagation on the SCC phenomenon. Three types of stress may affect the SCC susceptibility in pipeline steel. The first one is the constant load such as the pressure inside the pipe. The second one is the preload and the last one is the fluctuating loads such as wind or ground movements. Pipe bending or welding process can apply preload as a residual stress in pipeline steel. There is stress fluctuation in pipeline steel and the effect of such stress on crack initiation and propagation should not be neglected. It is reported that the SCC crack propagation near-neutral $\mathrm{pH}$ solution does not occur under constant loading and fluctuation loading is required to initiate and propagate the cracks [61-64]. Jia. et al. [65] studied the effect of 
constant loading and preloading on the SCC in X80 pipeline steel in near-neutral $\mathrm{pH}$ environment. They observed that preload do not change the SCC behavior in X80 steel near-neutral solution. However, the time of crack initiation near-neutral environment under constant load is decreased when preload is applied.

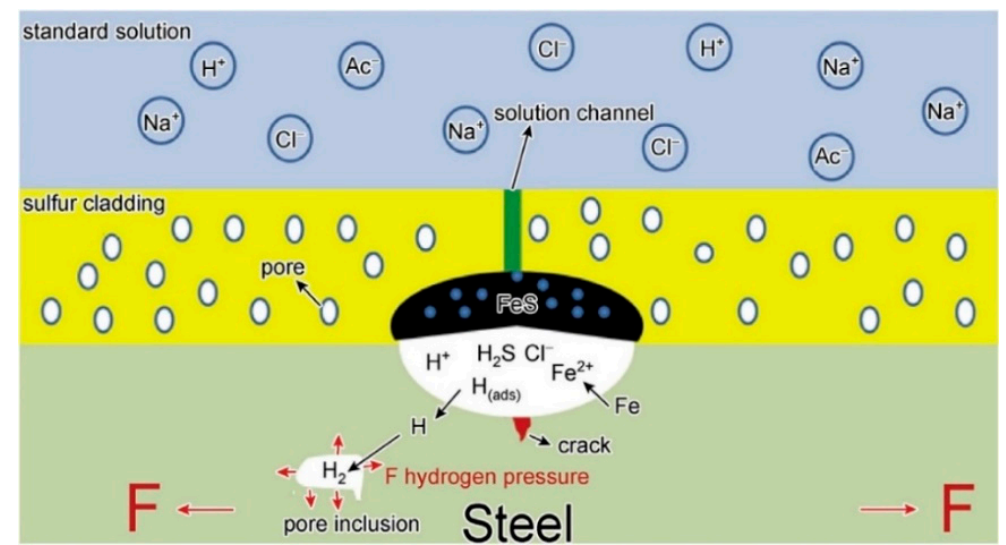

Figure 10. The SCC model for L360NS pipeline steel in sulfur melting cladding condition [9]. Reproduced with permission from [9], Elsevier, 2017.

\section{Effect of Different Elements on SCC Susceptibility}

There are several studies focused on the effects of different elements on the HIC and the SCC susceptibility in pipeline steel. No doubt, different elements play different roles on the SCC and the HIC susceptibility. The main elements playing a key role on SCC susceptibility are carbon, manganese, and phosphorus elements. These elements are recognized as segregation elements during solidification of steels such as pipeline steels. The mentioned elements are segregated at the center of thickness of pipeline slabs and create some hard phases and structures such as bainite and martensite. It has been reported that the manganese segregation ratio depends on carbon content [66]. It is important to note that low strength carbon steels can tolerate higher phosphorus segregation than high strength alloy steels [67]. Calcium element is usually added to pipeline steel due to its role on controlling the sulphur element $[68,69]$. Calcium element is combined with the sulphur and makes sulphide based inclusion which has a spherical shape. Therefore, the sulphur element is consumed by combining with the calcium and this phenomenon avoids the formation of more manganese sulphide inclusions. It is notable that manganese sulphide inclusion has an elongated shape and is considered as crack nucleation site $[10,70]$.

It has been reported that copper has a beneficial effect on both increasing the strength of steel and $\mathrm{HIC}$ resistance by producing $\mathrm{Cu}$-enriched fine precipitates [71]. Copper also makes a protective layer on the surface of steel and decrease the hydrogen diffusion inside the steel. Baba et al. [72] investigated the effect of copper addition on the prevention of hydrogen permeation in sour environment in pipeline steel. These authors concluded that copper creates an inner layer of corrosion product with $100 \mathrm{~nm}$ on the surface of steel preventing hydrogen entry inside the microstructure of steel.

\section{Effect of Crystallographic Texture and Meso-Texture on SCC Susceptibility}

There are several traditional methods, such as using micro-alloying elements, adding some elements, using some special heat treatments and reducing number of inclusions, to increase the SCC susceptibility in pipeline steels. However, most of such methods are not effective enough to increase the SCC susceptibility. Crystallographic texture has been recently considered as a novel technique which can reduce the SCC susceptibility in pipeline steels. There are a few studies focused on the role of texture on the SCC susceptibility in pipeline steel [60-62]. Arafin et al. [12] investigated the role of grain boundary character and crystallographic texture on the SCC susceptibility in X65 pipeline 
steel by electron backscatter diffraction (EBSD) and X-ray texture measurements. Figure 11 shows one SCC crack in X65 pipeline steel. As shown in this figure, the SCC crack gets two branches when it approaches to grains number 7 and 8 . It is important to note that the misorientation angle between grains $(7,13)$ and $(7,10)$ are higher than $15^{\circ}$ falling in the classification of high angle grain boundaries. Therefore, the boundaries between these grains with high energies provide an easy path for crack propagation. As shown with red circle, the SCC crack is deflected about $45^{\circ}$ when it reaches grain number 30. Calculation of misorientation between grains number $(30,31)$ and $(31,32)$ proves that the misoriatation angles between them are $12.3^{\circ}$ and $36.1^{\circ}$, respectively. This proves why the SCC crack deflects when it reaches grain number 30. Coincidence site lattice boundaries are categorized as low angle boundaries having a low energy. Therefore, such boundaries are not favorable for the SCC crack propagation. One should expect that the crack follows the grain boundary between grains number 37 and 38; however, the EBSD analysis shows that such boundary is from $\sum 11$ type boundary with a low energy. An interesting result was observed when the SCC crack reaches the grain number 39. The grain boundaries between grains number $(39,40)$, and $(40,41)$ are from low angle grain boundary (LAGB) and high angle grain boundary (HAGB), respectively. Surprisingly, the SCC crack has propagated though the grain boundary between grains number 39 and 40 which has a low energy. The EBSD analysis indicates that these grains have orientations close to the $\{110\} \|$ rolling plane with $<110>$ boundary rotation axis. This might be the main reason for resisting of mentioned path for crack propagation.

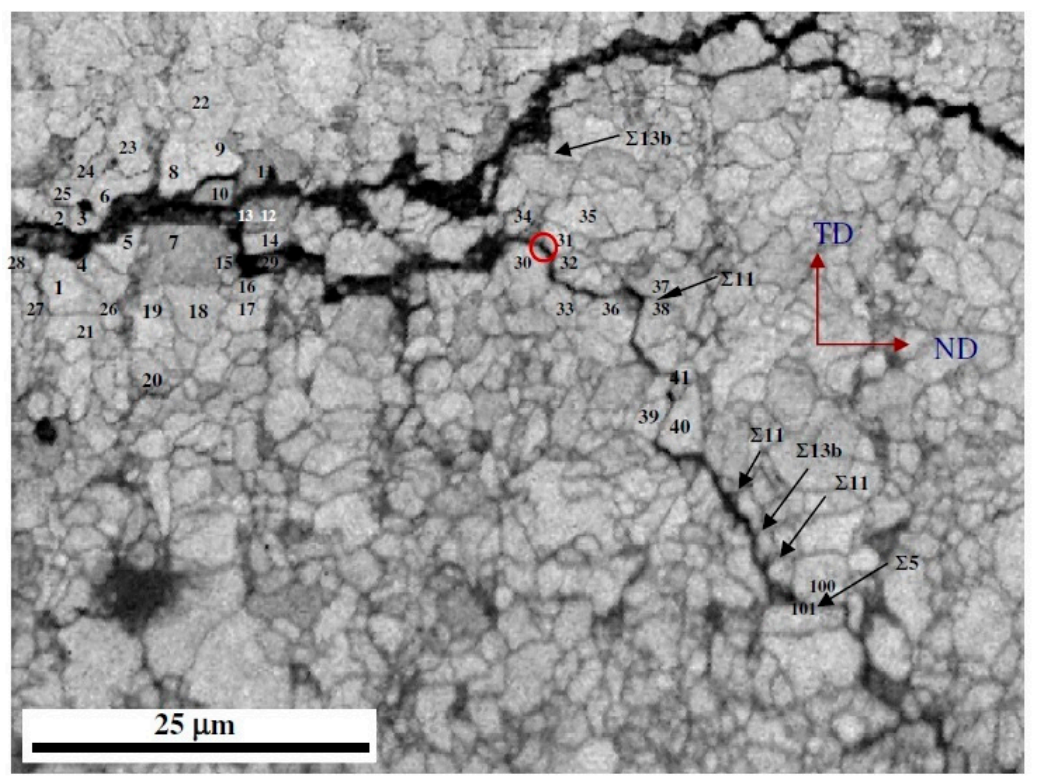

Figure 11. Electron backscatter diffraction (EBSD) map of the SCC crack propagation in X65 pipeline steel [12]. Reproduced with permission from [12], Elsevier, 2009.

The results of Arafin et al. [12] illustrated that the grain boundary character plays an important role in intergranular SCC. They also observed that CSL boundaries beyond the $\sum 13 \mathrm{~b}$ do not provide the resistance path for the crack propagation. Finally, they showed that the macro and miro-texture significantly affect the intergraular SCC. It is worth-mentioning that the study of texture on the SCC crack propagation is a novel method and there are a few researches in the literature. Control of texture and grain boundary character may be used to produce new pipeline steels with a higher resistance to the HIC and the SCC in the near future.

\section{Improvement of SCC Resistance}

There are some methods that can be considered as new ways to improve the pipeline steel performance against SCC cracking. Crystallographic texture and grain boundary engineering have a 
key role in increasing the SCC resistance in pipeline steel. Arafin et al. [12] investigated the role of texture on X65 pipeline steel and concluded that a new understanding of texture and grain boundary character will help to produce new pipeline steels with superior intergranular SCC resistance. They concluded that a large amount of CSL boundaries and LAGBs can avoid intergranular SCC crack propagation in pipeline steels. Such boundaries are provided by modifying the surface texture. It has been reported that some phases and microstructures have a better SCC resistance in pipeline steels. Bulger et al. [73] investigated the effect of microstructure in pipeline steels on SCC resistance in near-neutral $\mathrm{pH}$ and concluded that there is a possibility to improve the SCC resistance by providing the fine-grained bainite and ferrite microstructure. These authors also documented that the pipeline steels with ferrite and pearlite microstructure have a poor SCC resistance. Moreover, the role of inclusions on SCC crack initiation is considerable. Wang et al. [74] investigated role of inclusions on pitting corrosion and SCC in X70 pipeline steels in near-neutral $\mathrm{pH}$ environment. They concluded that oxide and silicon enriched inclusions are considered as SCC micro-crack initiation sites. Based on their observations, most of SCC micro-cracks propagated through ferrite grains in transgranular manner. Therefore, manufacturing a pipeline steel with low number of inclusions or with uniform distribution of inclusions would be desirable for a high SCC resistance in pipeline steels.

\section{Conclusions}

Based on the above-discussion, several factors playing a significant role on the SCC susceptibility in pipeline steels are as follow:

(1) Microstructure of steel plays a key role on the SCC crack initiation and propagation. Nature of the SCC cracks, specially transgranular crack propagation, highly depends on the microstructure of steel. Other metallurgical factors including grain size and grain boundaries become determinative factors during intergranular cracking.

(2) The effect of residual stresses in crack initiation and propagation should not be neglected. Tensile residual stress gives a high amount of mechanical driving force for crack initiation and short crack propagation.

(3) AC current density may affect the crack propagation by two ways. First, AC current may break down the insulation layer of pipeline steel and destroy the cathodic protection system. Secondly, AC current density affects the nature of the SCC crack. When there is no AC current, the SCC cracks propagate through intergranular manner and its mechanism is the anodic dissolution. However, with the presence of AC current, the SCC susceptibility is increased and the SCC cracks propagate through transgranular manner at high current densities.

(4) In a subsea environment, the permeation of sea water in the gaps will promote the peeling of the coating resulting in a complicated and more severe corrosion in pipeline steel by destroying the coating of pipeline steel.

(5) Addition of some elements to the pipeline steel have a substantial effect on the SCC susceptibility. For instance, Carbon, manganese and phosphorus elements are segregated at the center of thickness of pipeline slabs and make some hard phases and structures such as bainite and martensite. Copper also makes a protective layer on the surface of steel and decrease the hydrogen diffusion inside the steel.

(6) The SCC crack propagation near-neutral $\mathrm{pH}$ solution does not occur under constant loading and fluctuation loading is required to initiate and propagate the cracks. The time of crack initiation near-neutral environment under constant loading is decreased when preload is applied.

(7) Crystallographic texture plays a key role in SCC crack propagation. Grains with $\{111\} \|$ rolling plane and $\{110\} \mid$ |rolling plane, coincidence site lattice boundaries and low angle grain boundaries are recognized as crack resistant paths while grains with high angle grain boundaries provides easy path for intergranular SCC crack propagation. 
Acknowledgments: We would like to thank the Research Center of University of Bonab for the financial support of this study.

Conflicts of Interest: The author declares no conflict of interest.

\section{References}

1. Liu, Z.Y.; Li, X.G.; Du, C.W.; Lu, L.; Zhang, Y.R.; Cheng, Y.F. Effect of inclusions on initiation of stress corrosion cracks in X70 pipeline steel in an acidic soil environment. Corros. Sci. 2009, 51, 895-900. [CrossRef]

2. Shi, X.B.; Yan, W.; Wang, W.; Zhao, L.Y.; Shan, Y.Y.; Yang, K. HIC and SSC behavior of high-strength pipeline steels. Acta Metall. Sinica 2015, 28, 799-808. [CrossRef]

3. Hara, T.; Asahi, H.; Ogawa, H. Conditions of hydrogen-induced corrosion occurrence of X65 grade linepipe steels in sour environments. Corros. Sci. 2004, 60, 1113-1121. [CrossRef]

4. Shi, X.B.; Yan, W.; Wang, W.; Zhao, L.Y.; Shan, Y.Y.; Yang, K. Effect of microstructure on hydrogen induced cracking behavior of a high deformability pipeline steel. J. Iron Steel Res. 2015, 22, 937-942. [CrossRef]

5. Kim, W.K.; Koh, S.U.; Yang, B.Y.; Kim, K.Y. Effect of environment and metallurgical factors on hydrogen induced cracking. Corros. Sci. 2008, 50, 3336-3342. [CrossRef]

6. Maciejewski, J. The effects of sulfide inclusions on mechanical properties and failures of steel components. J. Fail. Anal. Prev. 2015, 15, 169-178. [CrossRef]

7. Mohtadi-Bonab, M.A.; Szpunar, J.A.; Razavi-Tousi, S.S. A comparative study of hydrogen induced cracking behavior in API 5L X60 and X70 pipeline steels. Eng. Fail. Anal. 2013, 33, 163-175. [CrossRef]

8. Mohtadi-Bonab, M.A.; Eskandari, M.; Karimdadashi, R.; Szpunar, J.A. Effect of different microstructural parameters on hydrogen induced cracking in an API X70 pipeline steel. Met. Mater. Int. 2017, 23, 726-735. [CrossRef]

9. Fan, Z.; Hu, X.; Liu, J.; Li, H.; Fu, J. Stress corrosion cracking of L360NS pipeline steel in sulfur environment. Petroleum 2017, 3, 377-383. [CrossRef]

10. Mohtadi-Bonab, M.A.; Eskandari, M.; Ghaednia, H.; Das, S. Effect of microstructural parameters on fatigue crack propagation in an API X65 pipeline steel. J. Mater. Eng. Perform. 2016, 25, 4933-4940. [CrossRef]

11. Arafin, M.A.; Szpunar, J.A. Effect of bainitic microstructure on the susceptibility of pipeline steels to hydrogen induced cracking. Mater. Sci. Eng. A 2011, 528, 4927-4940. [CrossRef]

12. Arafin, M.A.; Szpunar, J.A. A new understanding of intergranular stress corrosion cracking resistance of pipeline steel through grain boundary character and crystallographic texture studies. Corros. Sci. 2009, 51, 119-128. [CrossRef]

13. Wright, J. Inhibiting rust and corrosion to prevent machine failures. In Proceedings of the Machinary Lubrication Conference and Exhibition, Houston, TX, USA, 6-8 November 2018.

14. National Energy Board. Stress Corrosion Cracking on Canadian Oil and Gas Pipelines; Report No. MH-2-95; National Energy Board: Calgary, AB, Canada, 1996.

15. Aly, O.F.; Neto, M.M. Stress Corrosion Cracking, Developments in Corrosion Protection; Aliofkhazraei, M., Ed.; IntechOpen Limited: London, UK, 2014.

16. Sutcliffe, J.M.; Fessler, R.R.; Boyd, W.K.; Parkins, R.N. Stress corrosion cracking of carbon steel in carbonate solutions. Corrosion 1972, 28, 313-320. [CrossRef]

17. Beavers, J.A.; Harle, B.A. Mechanisms of high-pH and nearneutral-pH SCC of underground pipelines. Offshore Mech. Arct. Eng. 2003, 123, 147-151. [CrossRef]

18. Charles, E.A.; Parkins, R.N. Generation of stress corrosion cracking environments at pipeline surfaces. Corrosion 1995, 51, 518-527. [CrossRef]

19. Fang, B.Y.; Atrens, A.; Wang, J.Q.; Han, E.H.; Zhu, Z.Y.; Ke, W. Review of stress corrosion cracking of pipeline steels in "low" and "high" pH solutions. J. Mater. Sci. 2003, 38, 127-132. [CrossRef]

20. Mohtadi-Bonab, M.A.; Ghesmati-Kucheki, H. Important Factors on the Failure of Pipeline Steels with Focus on Hydrogen Induced Cracks and Improvement of Their Resistance: Review Paper. Met. Mater. Int. 2019. [CrossRef]

21. Kadhim, M.G.; Albdiry, M. A critical review on corrosion and its prevention in the oilfield equipment. J. Petrol. Res. Stud. 2017, 14, 162-189. 
22. Zhu, M.; Du, C.; Li, X.; Liu, Z.; Wang, S.; Zhao, T.; Jia, J. Effect of strength and microstructure on stress corrosion cracking behavior and mechanism of X80 pipeline steel in high $\mathrm{pH}$ carbonate/bicarbonate solution. J. Mech. Eng. Perform. 2014, 23, 1358-1365. [CrossRef]

23. Gonzalez, J.; Gutierrez-Solana, F.; Varona, J.M. The effects of microstructure, strength level, and crack propagation mode on stress corrosion cracking behavior of 4135 steel. Met. Mater. Trans. A 1994, 27, 281-290. [CrossRef]

24. Masouri, D.; Zafari, M.; Araghi, A. Sulfide stress cracking of pipeline-case history. In Proceedings of the NACE International, Corrosion 2008 Proceedings, New Orleans, LA, USA, 16-20 March 2008.

25. Lancsater, J. Handbook of Structural Welding: Processes, Materials and Methods in the Welding of Major Structures, Pipelines and Process Plant; Woodhead Publishing: Sawston, UK, 2003.

26. Roffey, P.; Davies, E.H. The generation of corrosion under insulation and stress corrosion cracking due to sulphide stress cracking in an austenitic stainless steel hydrocarbon gas pipeline. Eng. Fail. Anal. 2014, 44, 148-157. [CrossRef]

27. Elboujdaini, M.; Revie, R.W. Metallurgical factors in stress corrosion cracking (SCC) and hydrogen-induced cracking (HIC). J. Solid State Electrochem. 2009, 13, 1091-1099. [CrossRef]

28. Chen, W. Modeling and prediction of stress corrosion cracking of pipeline steels, Trends in Oil and Gas Corrosion Research and Technologies; Woodhead Publishing Series in Energy; Woodhead Publishing: Sawston, UK, 2017; pp. 707-748.

29. Hongliang, Y.; He, X.; Fuqiang, Y.; Lingyan, Z. Effect of film-induced stress on mechanical properties at stress corrosion cracking tip. Rare Met. Mater. Eng. 2017, 46, 3595-3600. [CrossRef]

30. Austen, I.M. Effective stress intensities in stress corrosion cracking. Int. J. Fract. 1976, 12, 253-263. [CrossRef]

31. Costin, W.L.; Lavigne, O.; Kotousov, A.; Ghomashchi, R.; Linton, V. Investigation of hydrogen assisted cracking in acicular ferrite using site-specific micro-fracture tests. Mater. Sci. Eng. A 2016, 651, 859-868. [CrossRef]

32. Wang, J.Q.; Atrens, A. SCC initiation for X65 pipeline steel in the high $\mathrm{pH}$ carbonate/bicarbonate solution. Corros. Sci. 2003, 45, 2199-2217. [CrossRef]

33. Chen, W.; van Boven, G.; Rogge, R. The role of residual stress in neutral pH stress corrosion cracking of pipeline steels-Part II: Crack dormancy. Acta Mater. 2007, 55, 43-53. [CrossRef]

34. Zhu, M.; Du, C.; Li, X.; Liu, Z.; Li, H.; Zhang, D. Effect of AC on stress corrosion cracking behavior and mechanism of X80 pipeline steel in carbonate/bicarbonate solution. Corros. Sci. 2014, 87, 224-232. [CrossRef]

35. Hosokawa, Y.; Kajiyama, F.; Fukuoka, T. Alternating current corrosion risk arising from alternating current-powered rail transit systems on cathodically protected buried steel pipelines and its measures. Corrosion 2004, 60, 408-413. [CrossRef]

36. Tan, T.C.; Chin, D.T. Ac corrosion of nickel in sulphate solutions. J. Appl. Electrochem. 1988, 18, 831-838. [CrossRef]

37. Goidanich, S.; Lazzari, L.; Ormellese, M.; Pedeferri, M. Influence of AC on Corrosion Kinetics for Carbon Steel, Zinc and Copper; CORROSION/2005, Paper No. 05189; NACE International: Houston, TX, USA, 2005.

38. Wendt, J.L.; Chin, D.T. The A.C. corrosion of stainless steel - II. The breakdown of passivity of ss304 in neutral aqueous solutions. Corros. Sci. 1985, 25, 889-900.

39. Muralidharan, S.; Kim, D.K.; Ha, T.H.; Bae, J.H.; Ha, Y.C.; Lee, H.G.; Scantlebury, J. Influence of alternating, direct and superimposed alternating and direct current on the corrosion of mild steel in marine environments. Desalination 2007, 216, 103-115. [CrossRef]

40. Vasudevan, S.; Lakshmi, J. Effects of alternating and direct current in electrocoagulation process on the removal of cadmium from waterea novel approach. Sep. Purif. Technol. 2011, 80, 643-651. [CrossRef]

41. Jiang, Z.; Du, Y.; Lu, M.; Zhang, Y.; Tang, D.; Dong, L. New findings on the factors accelerating AC corrosion of buried pipeline. Corros. Sci. 2014, 81,1-10. [CrossRef]

42. Wan, H.; Song, D.; Liu, Z.; Du, C.; Zeng, Z.; Yang, X.; Li, X. Effect of alternating current on stress corrosion cracking behavior and mechanism of X80 pipeline steel in near-neutral solution. J. Nat. Gas Sci. Eng. 2017, 38, 458-465. [CrossRef]

43. Luo, J.; Zhang, L.; Li, L.; Yang, F.; Ma, W.; Wang, K.; Zhao, X. Electrochemical corrosion behaviors of the X90 linepipe steel in NS4 solution. Nat. Gas. Ind. 2016, 3, 346-351. [CrossRef]

44. Zhu, M.; Du, C.W. A new understanding on AC corrosion of pipeline steel in alkaline environment. J. Mater. Eng. Perform. 2017, 26, 221-228. [CrossRef] 
45. Zhu, M.; Du, C.; Li, X.; Liu, Z.; Wang, S.; Li, J.; Zhang, D. Effect of AC current density on stress corrosion cracking behavior of $\mathrm{X} 80$ pipeline steel in high $\mathrm{pH}$ carbonate/bicarbonate solution. Electrochem. Acta 2014, 117, 351-359. [CrossRef]

46. Rodríguez, J.J.S.; Hernández, F.J.S.; González, J.E.G. The effect of environmental and meteorological variables on atmospheric corrosion of carbon steel, copper, zinc and aluminium in a limited geographic zone with different types of environment. Corros. Sci. 2003, 45, 799-815. [CrossRef]

47. Iakovleva, E.; Mäkilä, E.; Salonen, J.; Sitarz, M.; Sillanpää, M. Industrial products and wastes as adsorbents for sulphate and chloride removal from synthetic alkaline solution and mine process water. Chem. Eng. J. 2015, 259, 364-371. [CrossRef]

48. Mustapha, A.; Charles, E.A.; Hardie, D. Evaluation of environment-assisted cracking susceptibility of a grade X100 pipeline steel. Corros. Sci. 2012, 54, 5-9. [CrossRef]

49. Oskuie, A.A.; Shahrabi, T.; Shahriari, A.; Saebnoori, E. Electrochemical impedance spectroscopy analysis of X70 pipeline steel stress corrosion cracking in high $\mathrm{pH}$ carbonate solution. Corros. Sci. 2012, 61, 111-122. [CrossRef]

50. Yan, M.C.; Xu, J.; Yu, L.B.; Wu, T.Q.; Sun, C.; Ke, W. EIS analysis on stress corrosion initiation of pipeline steel under disbonded coating in near-neutral pH simulated soil electrolyte. Corros. Sci. 2016, 110, 23-34.

51. Kang, Y.W.; Chen, W.X.; Kania, R.; Boven, G.V.; Worthingham, R. Simulation of crack growth during hydrostatic testing of pipeline steel in near-neutral $\mathrm{pH}$ environment. Corros. Sci. 2011, 53, 968-975. [CrossRef]

52. Liu, Y.; Wang, J.W.; Liu, L.; Li, Y.; Wang, F.H. Study of the failure mechanism of an epoxy coating system under high hydrostatic pressure. Corros. Sci. 2013, 74, 59-70. [CrossRef]

53. Suna, F.; Ren, S.; Li, Z.; Liu, Z.; Li, X.; Du, C. Comparative study on the stress corrosion cracking of X70 pipeline steel in simulated shallow and deep sea environments. Mater. Sci. Eng. A 2017, 685, 145-153. [CrossRef]

54. Marshakov, A.I.; Ignatenko, V.E.; Bogdanov, R.I.; Arabey, A.B. Effect of electrolyte composition on crack growth rate in pipeline steel. Corros. Sci. 2014, 83, 209-216. [CrossRef]

55. Parkins, R.N.; Blanchard, W.K., Jr.; Delanty, B.S. Transgranular stress corrosion cracking of high-pressure pipelines in contact with solutions of near-neutral-pH. Corrosion 1994, 50, 394-408. [CrossRef]

56. Lu, B.T.; Luo, J.L.; Norton, P.R. Environmentally assisted cracking mechanism of pipeline steel in near-neutral pH groundwater. Corros. Sci. 2010, 52, 1787-1795. [CrossRef]

57. Lu, B.T.; Luo, J.L.; Norton, P.R.; Ma, H.Y. Effects of dissolved hydrogen and elastic and plastic deformation on active dissolution of pipeline steel in anaerobic groundwater of near-neutral pH. Acta Mater. 2009, 57, 41-49. [CrossRef]

58. Liu, Z.Y.; Wang, X.Z.; Du, C.W.; Li, J.K.; Li, X.G. Effect of hydrogen-induced plasticity on the stress corrosion cracking of X70 pipeline steel in simulated soil environments. Mater. Sci. Eng. A 2016, 658, 348-354. [CrossRef]

59. Mohtadi-Bonab, M.A.; Eskandari, M.; Szpunar, J.A. Role of cold rolled followed by annealing on improvement of hydrogen induced cracking resistance in pipeline steel. Eng. Fail. Anal. 2018, 91, 172-181. [CrossRef]

60. Mohtadi-Bonab, M.A.; Eskandari, M.; Szpunar, J.A. Effect of arisen dislocation density and texture components during cold rolling and annealing treatments on hydrogen induced cracking susceptibility in pipeline steel. J. Mater. Res. 2016, 31, 3390-3400. [CrossRef]

61. Fang, B.Y.; Han, E.H.; Zhu, Z.Y.; Wang, J.Q.; Ke, W. Stress corrosion cracking of pipeline steels. J. Mater. Sci. Technol. 2002, 18, 3-6.

62. Lu, B.T.; Luo, J.L. Crack initiation and early propagation of X70 Steel in simulated near-neutral pH groundwater. Corrosion 2006, 62, 723-731. [CrossRef]

63. Chen, W.X.; Kania, R.; Worthingham, R.; van Boven, G. Transgranular crack growth in the pipeline steels exposed to near-neutral $\mathrm{pH}$ soil aqueous solutions-The role of hydrogen. Acta Mater. 2009, 57, 6200-6214. [CrossRef]

64. Chen, W.; Wang, S.H.; Chu, R.; King, F.; Jack, T.R.; Fessler, R.R. Effect of precyclic loading on stress-corrosion-cracking initiation in an X-65 pipeline steel exposed to near-neutral $\mathrm{pH}$ soil environment. Metall. Mater. Trans. A 2003, 34, 2601-2608. [CrossRef] 
65. Jia, Y.Z.; Wang, J.Q.; Han, E.H.; Ke, W. Stress corrosion cracking of x80 pipeline steel in near-neutral pH environment under constant load tests with and without preload. J. Mater. Sci. Technol. 2011, 27, 1039-1046. [CrossRef]

66. Ghosh, G.; Rostron, P.; Garg, R.; Panday, A. Hydrogen induced cracking of pipeline and pressure vessel steels: A review. Eng. Fract. Mech. 2018, 199, 609-618. [CrossRef]

67. Dayal, R.K.; Grabke, H.J. Hydrogen induced stress corrosion cracking in low and high strength ferritic steels of different phosphorus content in acid media. Mater. Corros. 1987, 38, 409-416. [CrossRef]

68. Mohtadi-Bonab, M.A.; Szpunar, J.A.; Basu, R.; Eskandari, M. The mechanism of failure by hydrogen induced cracking in an acidic environment for API 5L X70 pipeline steel. Int. J. Hydrogen Energy 2015, 40, 1096-1107. [CrossRef]

69. Mohtadi-Bonab, M.A.; Eskandari, M. A focus on different factors affecting hydrogen induced cracking in oil and natural gas pipeline steel. Eng. Fail. Anal. 2017, 79, 351-360. [CrossRef]

70. Mohtadi-Bonab, M.A.; Eskandari, M.; Sanayei, M.; Das, S. Microstructural aspects of intergranular and transgranular crack propagation in an API X65 steel pipeline related to fatigue failure. Eng. Fail. Anal. 2018, 94, 214-225. [CrossRef]

71. Shi, X.; Yan, W.; Wang, W.; Shan, Y.; Yang, K. Novel Cu-bearing high-strength pipeline steels with excellent resistance to hydrogen-induced cracking. Mater. Des. 2016, 92, 300-305. [CrossRef]

72. Baba, K.; Mizuno, M.D.; Yasuda, K.; Nakamichi, H.; Ishikawa, N. Effect of Cu addition in pipeline steels on prevention of hydrogen permeation in mildly sour environments. Corrosion 2016, 72, 1107-1115. [CrossRef]

73. Bulger, J.T.; Lu, B.T.; Luo, J.L. Microstructural effect on near-neutral $\mathrm{pH}$ stress corrosion cracking resistance of pipeline steels. J. Mater. Sci. 2006, 41, 5001-5005. [CrossRef]

74. Wang, L.; Xin, J.; Cheng, L.; Zhao, K.; Sun, B.; Li, J.; Wang, X.; Cui, Z. Influence of inclusions on initiation of pitting corrosion and stress corrosion cracking of X70 steel in near-neutral pH environment. Corros. Sci. 2019, 147, 108-127. [CrossRef]

(C) 2019 by the author. Licensee MDPI, Basel, Switzerland. This article is an open access article distributed under the terms and conditions of the Creative Commons Attribution (CC BY) license (http://creativecommons.org/licenses/by/4.0/). 